\title{
Environmental Regulations and Trade Patterns in Hazardous Waste: Facility-level Analysis
}

\author{
Aleksandra Falkowska ${ }^{1}$ \\ ${ }^{1}$ Graduate School of Economics, Hitotsubashi University, Tokyo, Japan \\ Correspondence: Aleksandra Falkowska, Graduate School of Economics, Hitotsubashi University, 2-1 Naka, Kunitachi, \\ Tokyo 186-8601, Japan. E-mail: ed152109@g.hit-u.ac.jp
}

Received: May 2, 2018 Accepted: May 21, 2018 Online Published: July 17, 2018

doi:10.5539/res.v10n3p78

URL: https://doi.org/10.5539/res.v10n3p78

\begin{abstract}
This paper offers a fresh look at the pollution haven hypothesis (PHH) in the context of the waste management industry. Unlike previous research examining trade in waste products, the present study distinguishes between waste destined for final disposal and waste destined for recovery. Furthermore, it combines very disaggregated data with the highly flexible mixed logit model and a reliable measure of environmental policy stringency. Including all those elements in one analysis allowed for the uncovering of the dramatic differences in the reactions of individual waste generators to the environmental policy stringency of the destination country. Although there is no evidence confirming the PHH, a significant pollution haven effect has been found. While most facilities are deterred by the environmental policy stringency, there are also waste generators attracted by strict regulations.
\end{abstract}

Keywords: comparative advantage, environmental policy, hazardous waste, mixed logit model, pollution haven effect, pollution haven hypothesis, waste management

\section{Introduction}

The pollution haven literature is very rich, which is hardly surprising because if the pollution haven hypothesis (PHH) was confirmed, it would have important implications for the world economy and the environment. Knowing that the environmental policy stringency constitutes the key determinant of the polluting industries location decisions would surely encourage some countries to lower their environmental standards in order to increase their share of those industries. However, what researchers have been finding support for is rather a pollution haven effect, which means that environmental regulation stringency is only one determinant of industry location and usually other factors are more important. (Note 1)

The elusiveness of the idea of pollution havens continues to attract researchers who challenge it in many ways. Most studies are focused on manufacturing industries and investigate location decisions of polluting firms (Smarzynska \& Wei, 2001; Eskeland \& Harrison, 2003; Cole, 2004; Mulatu et al., 2010) as well as the trade patterns of pollution-intensive goods (Tobey, 1990; Grossman \& Kruger, 1991; Kellogg, 2007). Regardless of the approach, they find at best some support for a pollution haven effect without confirming the PHH. Moreover, as some researchers point out, the openness of a country to FDI (Foreign Direct Investment) can rather bring about good results in terms of environmental protection. Birdsall and Wheeler (1993) analyzed extensive data from Latin America and discovered that countries with protected economies are more likely to develop dirty industries, whereas countries with open economies usually favor cleaner industries and tend to import higher environmental standards from developed nations.

Inconclusive results of studies on the $\mathrm{PHH}$ with respect to manufacturing industries gave rise to the idea that one possible way to find its confirmation is to focus on the "dirtiest" industry of all. As Baggs (2009) put it: "Since hazardous waste is one of the most regulated and dirty goods imaginable, we might expect that, should any industry follow a pollution haven like trade pattern, it would be hazardous waste disposal." However, several studies either produced mixed evidence or at least did not confirm the PHH in its strongest form (Baggs, 2009; Kellenberg, 2012; Kellenberg \& Levinson, 2014). What all authors agree on is that, contrary to popular belief, developed countries are usually net importers of hazardous waste.

In addition to the research on trade flows, there is one study on location decisions of waste management firms. Stafford (2000) analyzed location patterns of the hazardous waste management industry in the United States and confirmed a pollution haven effect. 
The problem of pollution havens has been studied in many ways but, amazingly, the potential of toxic waste flows analysis remains almost unnoticed. This is especially true for the intra-EU trade in hazardous waste, which is worth studying for a number of reasons. First of all, more than $90 \%$ of EU's hazardous waste stays within the EU. Secondly, there is a substantial variation in the stringency levels of environmental regulations across countries. Finally, sufficiently detailed disaggregated data is available.

To the author's knowledge, there is no research that explicitly tests data on trade in hazardous waste within the EU for the pollution haven effect. However, one study uses EU's facility-level data on industrial waste flows to determine factors that influence firms' decisions on whether to export their waste or dispose of it locally (Fikru, 2012). According to this study, strict environmental policies do, indeed, encourage facilities to export their toxic waste. But this effect can be more than offset in the case of countries that are large and well endowed with capital because the big number of competing recycling centers drives the prices of waste management down and discourages firms from exporting waste.

Facility-level data for this research has been collected from the European Pollutant Release and Transfer Register (E-PRTR). Fikru (2012) used the same database. However, the present study covers a much longer period of time and adopts a completely different empirical approach.

Fikru (2012) investigated which characteristics of an origin country may play a role in determining the export intensity of firms. She did not consider the characteristics of a destination country, which are crucial in the case of this research. I fit conditional logit and mixed logit models in order to investigate the variables that affect the decision of an individual facility on where to export their hazardous waste. Special attention is paid to the role of the destination country's environmental policy. Even though it is a critical variable in testing the $\mathrm{PHH}$, finding an adequate measure of regulatory stringency poses a great challenge to researchers. The lack of a direct measure sometimes leads to choices that are too broad (e.g., GDP per capita) or, conversely, focused only on one aspect of environmental policy (e.g., environmental taxes). Needless to say, the wrong choice of the environmental policy variable makes the conclusions inaccurate. Therefore, I decided to use and compare two different measures. The first one, abbreviated as SER (Stringency of Environmental Regulations), is very similar to the ER index introduced by Kheder and Zugravu (2012) and consists of three components, which encapsulate various aspects of environmental policy: Multilateral environmental agreements ratified (MEAs), Membership in international non-governmental organizations (INGOs), and Energy efficiency. The second measure is a proxy for regulatory stringency (PRS). It combines two variables: Corruption Perception Index (CPI) which measures the quality of institutions, and thus the level of enforcement, and Income (PPS) per inhabitant which captures the demand for a clean environment. (Note 2)

The originality of this research lies in combining very disaggregated data with the most flexible and reliable of the discrete choice models and a comprehensive measure of environmental policy stringency. Moreover, unlike the existing literature, the present study assumes that environmental regulations may affect the facility's decision on where to export its waste in different ways, depending on whether it is destined for recovery or final disposal.

The remainder of this paper proceeds as follows. Section 2 outlines the theoretical background and the empirical model. Section 3 describes the data along with the sources. Section 4 presents and discusses the empirical results. The last section concludes the paper.

\section{Theoretical Background and Empirical Model}

\subsection{Theoretical Background}

One way to think about trade and the environment is to use a Heckscher-Ohlin framework in which a comparative advantage can be derived from the differences in environmental policy stringency levels. Countries with lax regulations or poor enforcement are expected to specialize in the production of pollution-intensive goods. Since waste management activities generate negative externalities, such countries should also have a comparative advantage in waste disposal services.

A well-known formal model of international trade in waste products was developed by Copeland (1991). Since he considers a small open economy with only two production factors, land and labor, a comparative advantage in waste disposal services is associated with land abundance. Copeland shows that if we do not take into account the possibility of illegal waste disposal, then the highest level of welfare is achieved by allowing free trade in waste disposal services and reducing negative externalities by using domestic policy instruments such as taxes. However, if this first-best policy cannot be implemented or enforced, then trade restrictions may serve as a second-best policy. This kind of scenario is common in the real world because taxes set at the socially optimal level can easily be high enough as to encourage firms to look for illegal ways of waste disposal. If the government is unable to enforce its policies effectively, it is welfare-improving to set a disposal tax below the socially optimal level and restrict the trade in waste products.

Since environmental policy measures, such as disposal taxes, influence the price of waste disposal, it seems plausible that, 
assuming free trade, countries with poor environmental controls may become pollution havens for the waste disposal industry. Grossman and Krueger (1991) argue that trade liberalization affects the environment in three ways. First, the pollution and resources depletion become more serious simply as a result of an increase in the scale of economic activity. Second, the transfer of technology can potentially lead to the reduction in pollution, at least per unit of output. Finally, there is also a composition effect which brings about greater specialization among countries, and thus can create pollution havens. It happens when the differences in the stringency level of environmental regulations become an important source of comparative advantage.

Investigating trade in waste products seems to be a good way of testing the PHH because waste disposal industry is considered pollution-intensive. However, there are many reasons why trade in waste is in fact very difficult to analyze. One obvious reason is the illegal trade, which is not captured by official statistics. Even the data on legal trade is sometimes incomplete or inaccurate, but problems with the reporting process are not limited to trade in waste products. One difficulty that is unique to waste is the fact that it can have either negative or non-negative price. Another one is that the waste management industry is not always polluting, but in some cases it can be considered clean. The readily available data on trade in waste do not reveal details that would allow distinguishing between waste that can be associated with negative externalities and waste that is, in fact, a valuable material. Unfortunately, treating all waste as homogeneous can lead to incorrect inferences. Existing research usually focuses on hazardous waste, probably because of the availability of necessary data. Another reason might be that most of the hazardous waste has to be disposed of and there is much less potential for recycling than in the case of non-hazardous waste (Albers, 2014). Nonetheless, this paper makes a distinction between waste destined for final disposal and waste destined for recovery. I assume that the latter can be, in some cases, a valuable material treated with a clean technology in the destination country.

\subsection{The Model}

The E-PRTR database allows identifying not only a facility that produces waste, but also a waste handler that receives it. However, since there is only country-level data on the destination characteristics, in the model each of the 2869 exporting facilities from 29 European countries is choosing among 28 destinations. (Note 3) I am going to fit and compare two types of discrete choice models in order to explain how destination countries are chosen for hazardous waste shipments. Both of them, the conditional logit model and the mixed logit model, are based on the random utility framework, which assumes that an individual makes a choice that maximizes their utility. In the case of this research, maximizing utility is equivalent to minimizing the cost of waste disposal.

The amount of money a facility needs to spend on waste disposal depends on the transportation cost and the disposal or recovery fee.

$$
C=t * d * q+f * q,
$$

where $t$ denotes transportation cost per tonne of waste per 1 kilometer, $d$ is the distance to the waste handler in kilometers, $q$ is the amount of waste in tonnes, and finally $f$ is the disposal or recovery fee.

Facilities included in this study are those which shipped at least part of their waste abroad. As a matter of fact, the majority of hazardous waste generators never do this because usually it is cheaper to treat waste domestically. So, what might be the reasons for exporting waste? First, sometimes the technology required to treat particular types of waste is available only abroad. Second, in some cases, it is simply less expensive. Let superscripts $D$ and $F$ refer to domestic and foreign respectively. A facility exports waste when:

$$
C^{F}<C^{D}
$$

After substituting in (1) and some simple manipulations we obtain:

$$
f^{F}<t^{D} * d^{D}-t^{F} * d^{F}+f^{D}
$$

I assume that the transportation fee is greater when a facility chooses a foreign waste handler instead of a domestic one. So the difference $t^{D} * d^{D}-t^{F} * d^{F}$ in (3) is some negative number which I define as $-P$. Equation (3) can be now simplified to:

$$
f^{F}<f^{D}-P
$$

It is clear that a facility exports waste if the fee charged by a foreign waste handler is lower than the domestic waste handler's fee less the difference in foreign and domestic transportation costs. Since transportation and bureaucratic costs in the case of exporting waste products are very large, this rarely happens. It is worth noting that sometimes a foreign waste handler that possesses technology unavailable in the country where a facility is located pays for recoverable waste, 
which otherwise would have to be disposed of domestically for a fee. In this case $f^{F}$ becomes negative because money paid by a foreign waste management firm to a facility can be subtracted from the overall cost of waste disposal.

Even though some facilities may profit from exporting waste, the majority of them choose the destination country so that the cost of waste disposal is minimal. This choice can be captured in the random utility framework. If the utility of facility $g$ choosing country $k$ from among $J$ alternatives is defined as $U_{g k}$, then country $k$ will be chosen when $U_{g k}>U_{g j}$ for $k \neq j$. As the true utility $U_{g j}$ is unknown, a researcher can only predict the facility's choice in terms of probability. The observable component of the utility, $V_{g j}$, can be computed based on the destination country's attributes, whereas a random component, $\varepsilon_{g j}$, can only be known to a facility making the decision.

$$
U_{g j}=V_{g j}+\varepsilon_{g j}
$$

Since the observable component is based on the attributes that determine the cost of waste disposal, (5) can be written as: (Note 4)

$$
U_{\mathrm{gij}}=\beta_{0}+\beta_{1} C_{g i j}+\varepsilon_{g i j},
$$

where $C_{g i j}$ is the cost of waste disposal incurred by facility $g$ for shipment $i$ to country $j, C_{g i j}=\mathrm{t} * d_{g j} * q_{g i}+\mathrm{f}_{j} * q_{g i}$. In order to compute the probability $P_{g i k}=P\left(U_{g i k}>U_{g i j}\right)$, a probability density function must be imposed on the random component $\varepsilon_{g i j}$. In the conditional logit model $\varepsilon_{g i j}$ follows the extreme value distribution and is assumed to be independent and identically distributed (iid). The probability of facility $g$ choosing country $k$ for shipment $i$ from among $J$ alternatives is computed as:

$$
P_{g i k}=\frac{e^{V_{g i k}}}{\sum_{j=1}^{J} e^{V_{g i j}}}=\frac{e^{Z_{g i k}^{\prime} \beta}}{\sum_{j=1}^{J} e^{Z_{g i j}^{\prime} \beta}},
$$

where $Z_{g i j}^{\prime}$ is a vector including explanatory variables (country's attributes determining the cost of disposal), and $\beta$ is a vector of coefficients obtained from the model. The conditional logit model assumes that, all else being equal, a facility's choice between two destinations is independent of what other destinations are available. Stated differently, the ratio $P_{g i k} / P_{g i j}$ is unaffected by the remaining probabilities. This property of conditional logit model is called the independence from irrelevant alternatives (IIA) and is often violated in the real world.

Several models have been developed in order to relax the IIA assumption. The mixed logit model is particularly flexible and differs from the conditional logit model in that it allows coefficients to vary across individuals or, in the case of this research, across facilities. Furthermore, the panel nature of data can be fully exploited (Greene, 2012). A facility's $g$ utility from alternative $j$ in time (choice situation) $t$ is:

$$
U_{g j t}=Z_{g j t}^{\prime} \beta_{g}+\varepsilon_{g j t},
$$


where $\beta_{g}$ differs across facilities. In order to estimate $U_{g j t}$ a researcher has to choose a distribution for random parameters (e.g., normal, uniform, triangular). In the situation when there is only one choice per facility, the probabilities are estimated as a weighted average of the standard logit formula evaluated at different values of random parameters $\beta$. The weights are given by the density $\mathrm{f}(\beta)$ :

$$
P_{g k}=\int\left(\frac{e^{Z_{g k}^{\prime} \beta}}{\sum_{j=1}^{J} e^{Z^{\prime}{ }^{\prime} \beta}}\right) f(\beta) d \beta
$$

The solution to (9) is obtained by simulation instead of direct integration, which would be infeasible (Greene, 2012).

In the case of panel data, a facility makes a sequence of choices, which can be defined as $\boldsymbol{k}=\left(k_{1}, k_{2}, \ldots, k_{T}\right)$. When a facility chooses one destination in each of the $T$ time periods, the probability of making this sequence of choices can be expressed as the product of logit formulas. The probability conditional on $\beta$ is:

$$
L_{\mathrm{gk}}(\beta)=\prod_{t=1}^{T}\left[\frac{e^{z_{g l t}^{\prime} \beta_{g}}}{\sum_{j=1}^{J} e^{z_{g i t}^{\prime} \beta_{g}}}\right]
$$

Finally, the unconditional probability is computed as the integral of the product in (10) over all values of $\beta$ :

$$
P_{\mathrm{gk}}=\int L_{\mathrm{gk}}(\beta) f(\beta) d \beta
$$

The (11) differs from (9) in that the product of logit formulas is integrated instead of just one logit formula (Train, 2009).

\section{Data}

\subsection{The Choice and Sources of Variables}

\subsubsection{Dependent Variable}

The dependent variable, CHOICE, is equal to one if facility $g$ exported waste to country $k$ and zero otherwise. There are 2869 facilities from 29 European countries which at least once exported hazardous waste in excess of 2 tonnes between 2007 and 2015. The total number of shipments amounts to 15249 (Note 5), and the choice set comprises of 28 European countries. (Note 6)

The data on shipments of hazardous waste comes from the already mentioned E-PRTR. It is quite unique in that it contains very disaggregated data which is based on calculation or actual measurements (instead of estimation), and thus can be considered reliable. Moreover, international comparisons are possible because all facilities have to report according to the same standards. However, the E-PRTR has also some limitations that should be taken into account while analyzing the data. First, the register covers on average 39\% (EC, 2013) of all hazardous waste transfers (the level of coverage differs depending on sector). This results from the thresholds associated with the facility's size and the volumes transferred. It can be problematic in the case of smaller countries and certain sectors. Second, some of the data is kept confidential. The most common reason for claiming confidentiality is the confidentiality of commercial or industrial information to protect a legitimate economic interest, including tax or statistical secrecy. The majority of facilities that have declared confidentiality are engaged in the waste management industry, the chemical industry as well as the production and processing of metals. Most commonly facilities do not reveal data on waste handler party name and address. (Note 7) Third, information on the size of reporting facilities is incomplete (Fikru, 2013), and thus cannot be used in this study. 


\subsubsection{Explanatory Variables}

Since the empirical model is based on the utility maximization (cost minimization) framework, the explanatory variables include the most important factors that affect the cost of disposing of waste abroad. Variables can be divided into two groups: those associated with the transportation cost and those associated with the disposal fee.

The first group consists of two variables: Distance and Border. The distance between countries is calculated as Euclidean distance between their capital cities. As the distance increases, so does the transportation cost. The fact of having to cross multiple borders is also important because the bureaucratic burden becomes greater with each additional transit country. In this study, however, I make only a simple distinction between a neighboring country and all other countries. The distance variable is expected to have a negative coefficient, while in the case of the Border variable the coefficient should be positive.

Actual data on the average disposal fees in countries from the sample is not available, so the second group includes variables that are assumed to determine disposal fees. The most important factors affecting the fees are related to the cost of constructing and running a waste management facility, the level of competition in the waste management market, and the stringency of environmental policy.

The cost of establishing and running a waste management facility depends on the cost of labor and the price of land. (Note 8) The labor component is captured by the labor cost levels (Lab. Cost). Labor cost levels mean the total average hourly labor costs in Euro in industry, construction, and services (except public administration, defense, compulsory social security). The cost of land is proxied by the population density variable (Pop. Dens.). I assume that the more densely populated a country is, the higher the cost of acquiring land. I expect the coefficients on the Lab. Cost and Pop. Dens. variables to be negative.

A disposal fee is determined not only by the cost of running a waste treatment facility, but also by the size of the market and the level of competition. These factors are captured by the total landfilling and recovery capacity (Total Cap)(Note 9). Since a large disposal and recovery market is assumed to decrease the cost of waste treatment, the coefficient on the Total Cap. variable should be positive.

Last but not least, the cost of recovery and disposal services can be affected by the general stringency of environmental regulations. If the PHH is valid in the case of waste management, a negative coefficient is expected on the policy stringency variable. However, the sign of this coefficient it not obvious when it comes to recovery services. Most of the hazardous waste cannot be recycled, but the part of it that can often requires a sophisticated technology, which has been developed in response to stringent regulations. (Note 10) Therefore, I expect that the negative impact of the policy stringency variable is at least weaker in the case of shipments destined for recovery. This effect should be captured by the positive coefficients on the interactions between regulatory stringency variables and the Recovery dummy. Finally, the stringency of environmental policy of an origin country is also taken into account. It is a part of a dummy variable (Policy Diff.) which equals 1 if the environmental policy of an origin country is more stringent than the environmental policy of a destination country and 0 otherwise. A positive coefficient on the Policy Diff. variable would mean that facilities are more likely to export waste to a country, whose environmental standards are less strict than the standards of a country they are located in. This would be in line with the PHH.

Finding a good measure of regulatory stringency is challenging. This paper uses and compares two different indicators. The choice of indicators was based on existing research, which proposes a variety of measures. Even though there is no single fully satisfying approach (Brunel \& Levinson, 2013), I believe Kheder and Zugravu (2012) introduced an aggregate indicator that successfully captures the differences in stringency levels of environmental policy across countries. Therefore, I selected it as the main indicator of regulatory stringency in this study. I constructed the other one, PRS, for the sake of comparison.

One difficulty in comparing the regulatory stringency among EU countries results from the fact that all EU Member States are supposed to follow similar standards. However, depending on the country, the level of enforcement can be very different. Accordingly, it is important that the indicator be as unbiased and comprehensive as possible. SER index looks at various aspects of environmental policy stringency by combining three components. The first one, MEAs (Multilateral environmental agreements ratified), is meant to capture the extent of concern for the environment in a country. The second one, INGOs (Membership in non-governmental organizations per million of population), measures the strength of civil society, which is known to pressure governments over the environmental protection issues. The last component is the energy efficiency (GDP/unit of energy used) variable, which captures the effectiveness of countries in enforcing their environmental policy. (Note 11) Similarly to Kheder and Zugravu (2012), I followed the technique of Z-score in calculating SER and gave all three components the same importance. However, the time period and data sources differ from those used by Kheder and Zugravu (2012). (Note 12) 
The second measure of regulatory stringency, PRS, integrates the Corruption Perception Index (CPI) and normalized income (PPS) per inhabitant. Both components are given the same weight and have been computed using the same Z-score method I applied to calculate SER. CPI is assumed to capture the quality of institutions, which affects the level of enforcement. Income per capita measures the demand for a clean environment.

Table 1. Description of the variables

\begin{tabular}{llll}
\hline Variable & Name & Unit of measurement & Sources \\
\hline Distance & Distance & 100 kilometers & CEPII Gravity Dataset \\
Border & Border & 1 if countries share a border and 0 otherwise & CEPII Gravity Dataset \\
Labor Cost & Lab. Cost & Euro & Eurostat \\
Population Density & Pop. Dens. & 100 Inhabitants per $k m 2$ & Eurostat \\
Total Capacity & Total Cap. & Hundred million tonnes & Eurostat \\
Stringency of & SER & Score on a 1-100 scale & IEA Database, Eurostat, \\
Environmental & & & The Yearbook of \\
Regulations & & & International Organizations \\
Proxy for Regulatory & PRS & Score on a 1-100 scale & Transparency International, \\
Stringency & & & Eurostat \\
\hline
\end{tabular}

\subsection{Descriptive Statistics}

The basic descriptive statistics for most variables are presented in Table 2. The variable Border, which is not included in the table, takes only values 1 and 0 .

Table 2. Descriptive statistics

\begin{tabular}{lrrrrrr}
\hline & Distance & Lab. Cost & Pop. Dens. & Total Cap. & SER & PRS \\
\hline Min & 0.19 & 2.60 & 0.16 & 0.01 & 1.00 & 1.00 \\
Mean & 13.11 & 20.79 & 1.25 & 0.77 & 36.78 & 37.81 \\
Max & 37.66 & 56.40 & 5.03 & 3.71 & 100.00 & 100.00 \\
SD & 7.05 & 12.84 & 1.05 & 0.95 & 24.89 & 24.47 \\
\hline
\end{tabular}

Table 3 shows the average values of variables for countries categorized according to whether they were chosen as destinations or not. We can see that those values differ considerably. As for the Border variable, it turns out that as much as $55.13 \%$ of all the shipments were sent to a neighboring country.

Table 3. Average values of explanatory variables depending on the value of the CHOICE variable

\begin{tabular}{rrrrrrr}
\hline CHOICE & Distance & Lab. Cost & Pop. Dens. & Total Cap. & SER & PRS \\
\hline 0 & 13.44 & 20.83 & 1.22 & 0.75 & 36.34 & 37.25 \\
1 & 6.56 & 31.17 & 2.49 & 2.01 & 48.72 & 52.84 \\
\hline
\end{tabular}

As expected, the average distance between pairs of countries that traded wastes with each other is shorter than between those that did not engage in bilateral waste trade. Similarly, the average capacity of countries that were chosen as destinations is larger than that of countries that were not. The chosen countries had, on average, more stringent regulations, but this fact does not imply that there is no pollution haven effect. Surprisingly, the destination countries seem to be more densely populated and have higher labor cost levels. The possible reasons for these counterintuitive results will be explored in the next section.

Figure 1 presents the content of Table 3 in percentage terms. It allows for comparing the magnitudes of the differences in the values of explanatory variables, depending on the value of the CHOICE variable. 


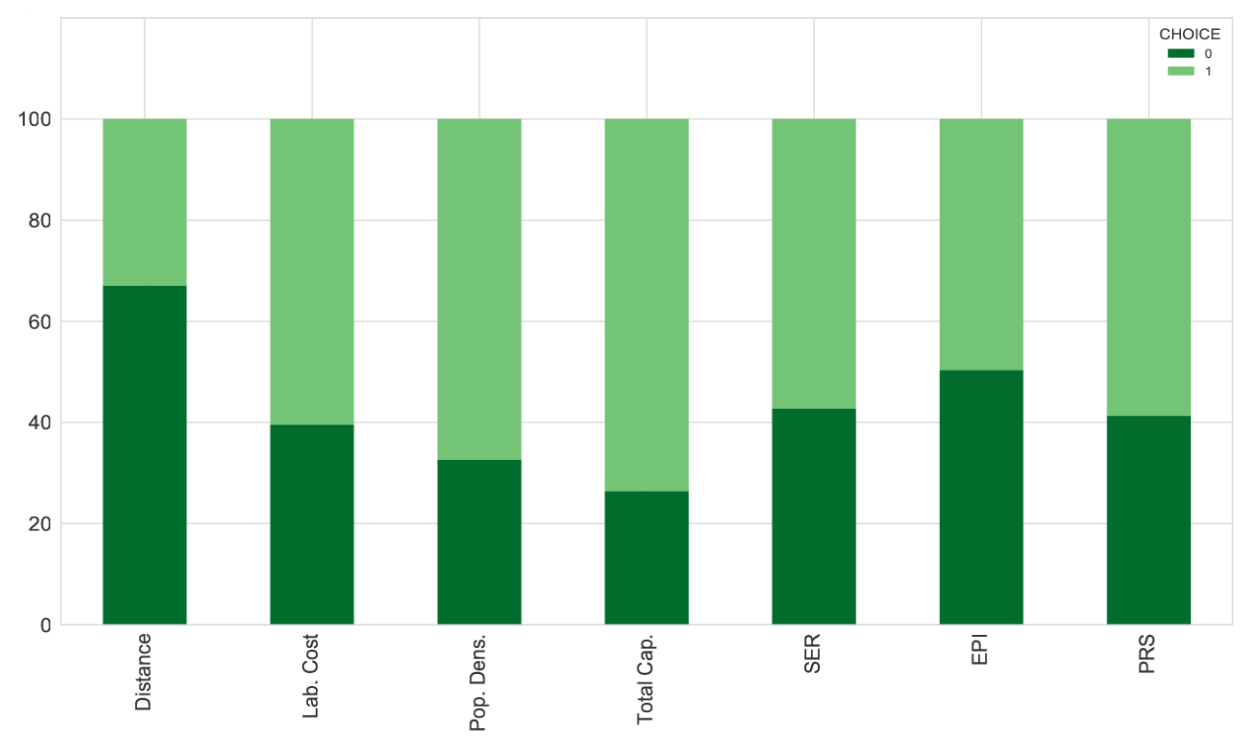

Figure 1. Differences in the average values of explanatory variables depending on the value of the CHOICE variable. Source: Own elaboration

\section{Empirical Results}

\subsection{Estimation}

I estimated eight different specifications. Table 4 and Table 5 report the results of specifications (1) to (4), and (5) to (8) respectively. Models in Table 5 are similar to those in Table 4 except they include interactions with the dummy variable Recovery. Specifications (1), (2), (5), and (6) are conditional logit models. Specifications (3), (4), (7), and (8) are mixed logit models. Specifications (1), (3), (5), and (7) include SER, whereas specifications (2), (4), (6), and (8) include PRS as the environmental policy stringency variable.

The conditional logit model has been used before in the context of waste shipments. Alberini and Frost (1999) investigated the determinants of American halogenated solvent waste generators' choice of the destination state for their waste. They fitted two separate conditional logit models, one for the shipments slated for landfilling, and the other one for the shipments slated for incineration. (Note 13)

I decided to test the conditional logit specifications with the Hausman-McFadden test for independence of irrelevant alternatives (IIA). Since they failed the test, I also fitted mixed logit models that relax the IIA assumption. In fact, the mixed logit models yield a higher log likelihood value, which means they are more efficient. However, as Train (2009) suggests, violation of IIA in the case of estimating average preferences is acceptable, provided a researcher treats the model as an approximation. 
Table 4. Conditional logit and mixed logit estimates

\begin{tabular}{|c|c|c|c|c|}
\hline & \multicolumn{4}{|c|}{ Dependent variable: } \\
\hline & \multicolumn{4}{|c|}{ CHOICE } \\
\hline & (1) & $(2)$ & $(3)$ & (4) \\
\hline Distance & $-0.11^{* * *}(0.003)$ & $-0.11^{* * *}(0.003)$ & $-0.15^{* * *}(0.01)$ & $-0.14^{* * *}(0.01)$ \\
\hline Border & $1.48^{* * *}(0.02)$ & $1.48^{* * *}(0.02)$ & $2.50^{* * *}(0.05)$ & $2.82^{* * *}(0.06)$ \\
\hline SER & $-0.01^{* * *}(0.001)$ & & $-0.01^{* * *}(0.002)$ & \\
\hline PRS & & $-0.01^{* * *}(0.001)$ & & $-0.005^{* *}(0.002)$ \\
\hline Policy Diff. & $0.35^{* * *}(0.03)$ & $0.09^{* * *}(0.03)$ & $0.43^{* * *}(0.05)$ & $0.18^{* * *}(0.04)$ \\
\hline Total Cap. & $0.79^{* * *}(0.01)$ & $0.68^{* * *}(0.01)$ & $1.19^{* * *}(0.01)$ & $1.07^{* * *}(0.01)$ \\
\hline Lab. Cost & $0.09^{* * *}(0.002)$ & $0.08^{* * *}(0.002)$ & $0.12^{* * *}(0.003)$ & $0.14^{* * *}(0.003)$ \\
\hline Pop Dens. & $0.48^{* * *}(0.01)$ & $0.56^{* * *}(0.01)$ & $0.58^{* * *}(0.02)$ & $0.76^{* * *}(0.02)$ \\
\hline Observations & 15249 & 15249 & 15249 & 15249 \\
\hline Log Likelihood & -28137 & -28394 & -22228 & -22291 \\
\hline
\end{tabular}

All of the coefficients reported in Table 4 are highly significant and have the same signs regardless of the specification. Their magnitude is similar for the two conditional logit models and for the two mixed logit models. Generally, mixed logit specifications tend to have larger coefficients than conditional logit specifications. It is worth noting that changing between the environmental policy stringency variables has only a small effect on the coefficients.

The general conclusions are mostly the same for the first four models. The coefficients on the Distance, Border, and Total Cap. variables have the expected signs. Consistent with intuition, the longer the distance to a country, the less attractive it is as a destination for waste shipments. Sharing a border with a waste generator's country works in the opposite direction, making a potential destination more attractive. The positive coefficient on the waste treatment capacity variable indicates that countries with a large waste management industry are more likely to be chosen as destinations for waste shipments.

The signs of the coefficients on the labor cost variable and the population density variable are opposite of what might be expected. As for the labor cost, a similar effect appears in Levinson (1996), Alberini and Frost (1999) as well as Stafford (2000). Several explanations are given. First, it is possible that the labor cost variable captures general economic activity in a country, which increases the demand for disposal services, and thus the disposal capacity. It is also possible that the cost of labor is not an important factor determining the disposal fees because the hazardous waste management industry is not very labor intensive. The positive coefficient on the Pop. Dens. variable might result from the correlation with the general economic activity of a country or some unobserved factors, which make a country attractive for waste shipments. 
Table 5. Conditional logit and mixed logit estimates with interaction terms

\begin{tabular}{|c|c|c|c|c|}
\hline & & Dependen & at variable: & \\
\hline & & $\mathrm{CH}$ & OICE & \\
\hline & (5) & (6) & (7) & (8) \\
\hline Distance & $-0.12^{* * *}(0.003)$ & $-0.11^{* * *}(0.003)$ & $-0.13^{* * *}(0.009)$ & $-0.14^{* * *}(0.01)$ \\
\hline Border & $1.47^{* * *}(0.02)$ & $1.50^{* * *}(0.02)$ & $2.61^{* * *}(0.07)$ & $2.71^{* * *}(0.08)$ \\
\hline SER & $0.004^{* * *}(0.001)$ & & $-0.01^{* * *}(0.002)$ & \\
\hline SER x Recovery & $-0.02^{* * *}(0.002)$ & & $-0.02^{* * *}(0.002)$ & \\
\hline PRS & & $-0.001 \quad(0.001)$ & & $-0.006^{* *}(0.002)$ \\
\hline PRS x Recovery & & $-0.01^{* * *}(0.002)$ & & $-0.005^{* *}(0.002)$ \\
\hline Policy Diff. & $0.31^{* * *}(0.06)$ & $-0.37^{* * *}(0.05)$ & $0.14 \quad(0.09)$ & $-0.76^{* * *}(0.09)$ \\
\hline Policy Diff. x Recovery & $0.03 \quad(0.07)$ & $0.65^{* * *}(0.06)$ & $0.003 \quad(0.09)$ & $0.69^{* * *}(0.08)$ \\
\hline Total Cap. & $0.79^{* * *}(0.008)$ & $0.69^{* * *}(0.007)$ & $1.32^{* * *}(0.03)$ & $1.10^{* * *}(0.03)$ \\
\hline Lab. Cost & $0.09^{* * *}(0.002)$ & $0.08^{* * *}(0.002)$ & $0.14^{* * *}(0.004)$ & $0.13^{* * *}(0.005)$ \\
\hline Pop. Dens. & $0.48^{* * *}(0.007)$ & $0.56^{* * *}(0.008)$ & $0.63^{* * *}(0.02)$ & $0.71^{* * *}(0.03)$ \\
\hline Observations & 15249 & 15249 & 15249 & 15249 \\
\hline Log Likelihood & -27941 & -28215 & -22016 & -22070 \\
\hline
\end{tabular}

Finally, the negative and significant coefficients on the SER and PRS variables suggest the presence of a pollution haven effect. The positive coefficient on the Policy Diff. variable further confirms this conclusion. Stringent regulations of a destination country deter facilities from shipping there. At the same time facilities are attracted by the standards lower than their own country's standards.

Adding interaction terms (see Table 5) revealed that, contrary to predictions, hazardous waste intended for recovery follows a pattern consistent with the presence of a pollution haven effect even more clearly than waste destined for disposal. It is possible that this results from EU legislation aiming at discouraging hazardous waste shipments to lower income countries, especially if it is intended for final disposal. Another plausible explanation is linked to the fact that shipments destined for recovery account for almost $70 \%$ of all shipments included in the sample. It is still possible that some of these shipments follow the PH like pattern. However, this prediction could be confirmed only if the data specifying a treatment option in more detail was available. It should be also noted that almost all coefficients on the Policy Diff. variable as well as on the interaction between this variable and the Recovery dummy are insignificant in specifications including SER. However, they are significant in specifications including PRS and suggest that hazardous waste tends to travel from countries with lax regulations to countries with strict policies. Moreover, this effect appears to be much stronger in the case of waste destined for final disposal. These conclusions differ slightly from those drawn based on specifications 2 and 4.

\subsection{Discussion}

Analysis of the coefficients in Table 5 revealed that individual facilities place different values on destination country characteristics. The data allows only for the distinction between two kinds of operations: recovery and disposal. Especially recovery is a very broad category, including recycling and incineration with energy recovery, which are very different ways of dealing with waste. However, the most important consideration for this study is the fact that generally, recovery operations require more advanced technology than disposal operations. (Note 14) Sometimes only countries with high environmental protection standards possess the state of the art technology because stringent regulations have fostered innovations in the waste management industry (consistent with the Porter hypothesis). This explains why some facilities have a positive coefficient on the environmental policy stringency variable. Using the mixed logit model, it is possible to pinpoint the share of facilities that have a positive coefficient on the regulatory stringency variable. 
Table 6. Standard deviations and means of the coefficients (Model (3))

\begin{tabular}{cccccccc}
\hline & & & & & \multicolumn{2}{c}{ Policy } \\
& Distance & Border & Lab. Cost & Pop. Dens. & Total Cap. & SER & Diff. \\
\hline SD & $0.13 * * *$ & $2.52 * * *$ & $0.11 * * *$ & $0.94 * * *$ & $0.85 * * *$ & $0.05 * * *$ & $1.69 * * *$ \\
Mean & $-0.14 * * *$ & $2.50 * * *$ & $0.12 * * *$ & $0.58 * * *$ & $1.19 * * *$ & $-0.006 * * *$ & $0.42 * * *$ \\
\hline
\end{tabular}

Table 6 presents standard deviations and means of the coefficients estimated with the specification (3). With this information, the share of facilities with positive and negative coefficients can be determined for each variable. I will focus especially on SER because it is a crucial variable in this study.

The coefficient of SER is normally distributed with mean -0.006 and standard deviation 0.05 . (Note 15) The cumulative standard normal distribution evaluated at $0.006 / 0.05=0.12$ is 0.548 , which indicates that about $55 \%$ of facilities are estimated to have negative SER coefficients. About $45 \%$ of facilities are attracted by the stringency of environmental regulations. Since shipments intended for recovery account for about $70 \%$ of all shipments in the sample, some of them must be facilities exporting waste for recovery. Presumably, many waste generators actually sell waste products because they contain valuable materials that can be recovered. However, it is impossible to confirm this prediction with the available data.

The fact that there are two groups of facilities, one attracted and the other one deterred by the stringency of environmental regulations, can also be clearly seen from the plot of the conditional distribution for SER (see Figure 2).

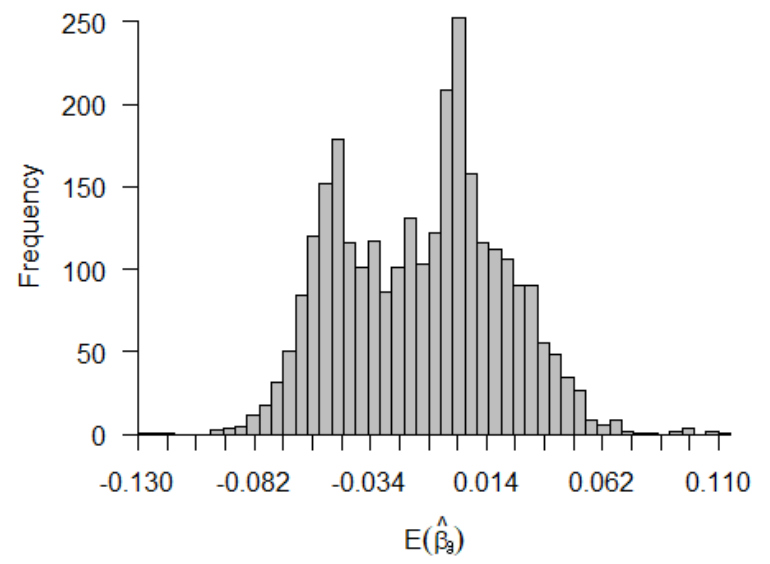

Figure 2. Conditional distribution for SER (Model (7)).

\section{Source: Own elaboration}

In order to get an idea of the importance of the SER variable in determining the destination country for hazardous waste shipments, it is useful to analyze the change in the predicted probability of receiving a shipment from a one standard deviation increase in SER. (Note 16) Table 7 shows this change for each country from the choice set. Since there is a large group of facilities that place a positive value on SER, we can expect that in some cases the predicted probability of receiving a shipment will increase as a result of implementing more stringent regulations. In fact, Table 7 confirms that five countries would import more waste in such situation.

Countries in Table 7 are ranked based on the SER score, with the highest score at the top. It is clear that negative values are concentrated especially in the bottom part of the table. This means that countries that would experience a decrease in waste imports as a consequence of implementing more stringent regulations are those that have relatively lax environmental policies.

The magnitude of change in the predicted probability varies a lot across countries. The three biggest importers are Germany, France, and Belgium. Germany and France, which have high values of SER, would experience a moderate change in the predicted probability of receiving a shipment as a result of an increase in the stringency of environmental policy. In contrast, in the case of Belgium, which has much laxer regulations, the predicted probability would decrease by 
as much as $30 \%$.

For the sake of comparison, the same calculations have been made for the Total Cap. variable. (Note 17) The results are presented in Table A1 in the appendix. Generally, a change in the total disposal and recovery capacity of a destination country seems to have a larger effect on the exporting facility's choice than the similar (1 SD) change in the value of the environmental policy stringency variable.

Table 7. Change in predicted probabilities from an increase of SER by 1 SD (calculated for Model (3))

\begin{tabular}{|c|c|c|c|c|c|}
\hline Country & $\begin{array}{r}\text { Predicted } \\
\text { Probabilities }\end{array}$ & $\begin{array}{r}\text { Probabilities } \\
\text { after an SER } \\
\text { increase }\end{array}$ & $\begin{array}{r}\text { Difference in } \\
\text { Predicted } \\
\text { Probabilities }\end{array}$ & $\begin{array}{r}\text { Percentage } \\
\text { Change }\end{array}$ & SER \\
\hline Norway & 0.024 & 0.021 & -0.003 & -12.500 & 99.629 \\
\hline Luxembourg & 0.013 & 0.018 & 0.005 & 38.462 & 90.018 \\
\hline Denmark & 0.006 & 0.006 & 0.000 & 0.000 & 73.903 \\
\hline Sweden & 0.008 & 0.008 & 0.000 & 0.000 & 69.838 \\
\hline Germany & 0.348 & 0.370 & 0.022 & 6.322 & 61.351 \\
\hline France & 0.109 & 0.130 & 0.021 & 19.266 & 55.515 \\
\hline Finland & 0.010 & 0.006 & -0.004 & -40.000 & 49.830 \\
\hline United Kingdom & 0.077 & 0.081 & 0.004 & 5.195 & 48.913 \\
\hline Netherlands & 0.084 & 0.099 & 0.015 & 17.857 & 43.753 \\
\hline Ireland & 0.019 & 0.012 & -0.007 & -36.842 & 42.151 \\
\hline Austria & 0.024 & 0.014 & -0.010 & -41.667 & 40.365 \\
\hline Latvia & 0.003 & 0.002 & -0.001 & -33.333 & 38.563 \\
\hline Slovenia & 0.007 & 0.005 & -0.002 & -28.571 & 37.805 \\
\hline Lithuania & 0.002 & 0.001 & -0.001 & -50.000 & 32.738 \\
\hline Italy & 0.028 & 0.020 & -0.008 & -28.571 & 30.499 \\
\hline Spain & 0.015 & 0.009 & -0.006 & -40.000 & 29.529 \\
\hline Belgium & 0.163 & 0.115 & -0.048 & -29.448 & 25.063 \\
\hline Romania & 0.006 & 0.006 & 0.000 & 0.000 & 25.037 \\
\hline Estonia & 0.002 & 0.001 & -0.001 & -50.000 & 21.910 \\
\hline Poland & 0.006 & 0.005 & -0.001 & -16.667 & 21.142 \\
\hline Cyprus & 0.004 & 0.001 & -0.003 & -75.000 & 20.168 \\
\hline Croatia & 0.005 & 0.002 & -0.003 & -60.000 & 16.977 \\
\hline Hungary & 0.004 & 0.002 & -0.002 & -50.000 & 14.249 \\
\hline Bulgaria & 0.008 & 0.006 & -0.002 & -25.000 & 13.439 \\
\hline Slovakia & 0.004 & 0.002 & -0.002 & -50.000 & 11.013 \\
\hline Czech Republic & 0.005 & 0.002 & -0.003 & -60.000 & 10.663 \\
\hline Portugal & 0.006 & 0.002 & -0.004 & -66.667 & 4.501 \\
\hline Greece & 0.010 & 0.003 & -0.007 & -70.000 & 2.256 \\
\hline
\end{tabular}

\section{Concluding Remarks}

This research has addressed the hotly debated PHH in a novel way, using highly disaggregated data on international waste flows and the mixed logit model, which is much more flexible than most other discrete choice methods. The basic findings are consistent with the existing literature. Well developed countries tend to have larger waste management markets, better technology, and thus a comparative advantage in the waste treatment activities. There is no evidence strong enough to support the PHH with respect to the waste management industry. Nonetheless, this study revealed a significant pollution haven effect, albeit smaller in magnitude than some other factors influencing waste generators' choices. 
The fact that I used a mixed logit approach allowed me to confirm the prediction that some facilities do not follow a pattern consistent with the presence of a pollution haven effect. In fact, as much as $45 \%$ of all exporting facilities from the sample were attracted by the stringency of environmental regulations. Perhaps many of those are the facilities whose waste can be recovered and has a positive price, but only if it is shipped to technologically advanced countries with high environmental standards. This prediction, however, could not be confirmed with the available data.

The results suggest that EU policies are rather efficient in reducing trade in hazardous waste, but they seem to be too strict. In the case of hazardous waste, not only waste destined for disposal, but also waste that is going to be recycled is subject to very costly and lengthy bureaucratic procedures. This often makes international shipments too expensive for facilities and waste is eventually landfilled in the country of origin or, worse, is exported illegally. The first option might be especially relevant to low-income countries which have access to cheap disposal services. It is probably not very frequent that a facility from a low-income country whose waste can be efficiently recovered with advanced technology profits from recovering waste in a high-income country despite bureaucratic costs. It must be more common that a facility from a high-income country recovers waste in a low-income country because of the difference in prices. This is presumably why this study confirms a pollution haven effect with respect to the recovery of hazardous waste. Trade in waste intended for disposal is very rare because of EU legislation. Possibly many of the reported shipments refer to waste which requires advanced technology to be disposed of. Waste generators who look for the cheapest way to dispose of waste are likely engaged in illegal trade. Therefore, not only domestic regulations, but also international agreements should be designed in such a way as to take account of possible illegal activities.

Finally, an important conclusion that can be drawn from this study is that any further research on the relationship between environmental policy and the waste management industry should take into account the fundamental differences among various types of waste products and treatment methods. Hopefully, in the future, more detailed data will be available. This research could be greatly enhanced if it was possible to distinguish between recycling and incineration with energy recovery. Another way to improve the approach presented in this paper would be to include waste generators' characteristics. Unfortunately, only a few facilities reported the relevant data to the E-PRTR during the study period.

\section{References}

Alberini, A., \& Frost, S. (1999). Forcing firms to think about the future: Economic incentives and the fate of hazardous waste. Working paper, 99-26, University of Colorado at Boulder. https://www.colorado.edu/economics/papers/papers99/wp99-26.pdf

Alberini, A., \& Frost, S. (2007). Forcing firms to think about the future: Economic incentives and the fate of hazardous waste. Environmental and Resource Economics, 36(4), 451-474. https://doi.org/10.1007/s10640-006-9037-8

Albers, J. (2014). Responsibility and liability in the context of transboundary movements of hazardous wastes by sea: existing rules and the 1999 Liability Protocol to the Basel Convention, volume 29. Springer. https://www.springer.com/gp/book/9783662433485

Ambec, S., Cohen, M. A., Elgie, S., \& Lanoie, P. (2013). The porter hypothesis at 20: can environmental regulation enhance innovation and competitiveness? Review of Environmental Economics and Policy, 7(1), 2-22. http://www.rff.org/files/sharepoint/WorkImages/Download/RFF-DP-11-01.pdf

Baggs, J. (2009). International trade in hazardous waste. Review of International Economics, 17(1), 1-16. https://doi.org/10.1111/j.1467-9396.2008.00778.x

Birdsall, N., \& Wheeler, D. (1993). Trade policy and industrial pollution in Latin America: where are the pollution havens? The Journal of Environment \& Development, 2(1), 137-149. https://doi.org/10.1177/107049659300200107

Brunel, C., \& Levinson, A. (2013). Measuring environmental regulatory stringency. OECD Trade and Environment Working Papers, 2013(5).

https://www.oecd-ilibrary.org/trade/measuring-environmental-regulatory-stringency_5k41t69f6f6d-en

Cole, M. A. (2004). Trade, the pollution haven hypothesis and the environmental Kuznets curve: examining the linkages. Ecological Economics, 48(1), 71-81. https://doi.org/10.1016/j.ecolecon.2003.09.007

Copeland, B. R. (1991). International trade in waste products in the presence of illegal disposal. Journal of Environmental Economics and Management, 20(2), 143-162. https://doi.org/10.1016/0095-0696(91)90047-M

Copeland, B. R., \& Taylor, M. S. (2004). Trade, growth, and the environment. Journal of Economic Literature, 42(1), 7 71. https://doi.org/10.1257/002205104773558047

EC (2009). Working paper on three-yearly review of the E-PRTR regulation. 
EC (2013). Report from the Commission to the European Parliament and the council on progress in implementing regulation (EC) 166/2006 concerning the establishment of a European Pollutant Release and Transfer Register (E-PRTR).

Eskeland, G. S., \& Harrison, A. E. (2003). Moving to greener pastures? Multinationals and the pollution haven hypothesis. Journal of Development Economics, 70(1), 1-23. https://doi.org/10.1016/S0304-3878(02)00084-6

Fikru, M. G. (2012). Transboundary movement of hazardous waste: Evidence from a new micro data in the European Union. Review of European Studies, 4(1). http://citeseerx.ist.psu.edu/viewdoc/download?doi=10.1.1.677.3871\&rep=rep1\&type=pdf

Fikru, M. G. (2013). Improving mandatory environmental data reporting for comparable and reliable environmental performance indicators. In Márquez, F. P. G., editor, Engineering Management. InTech. https://doi.org/10.5772/54499

Greene, W. H. (2012). Econometric analysis (International edition). Pearson.

Grossman, G. M., \& Krueger, A. B. (1991). Environmental impacts of a North American Free Trade Agreement. National Bureau of Economic Research. https://doi.org/10.3386/w3914

Kellenberg, D. (2012). Trading wastes. Journal of Environmental Economics and Management, 64(1), 68-87. https://doi.org/10.1016/j.jeem.2012.02.003

Kellenberg, D., \& Levinson, A. (2014). Waste of effort? International environmental agreements. Journal of the Association of Environmental and Resource Economists, 1(1/2), 135-169. https://doi.org/10.1086/676037

Kellogg, R. et al. (2007). The pollution haven hypothesis: significance and insignificance. Working paper, Berkley. http://ageconsearch.umn.edu/bitstream/21191/1/sp06ke01.pdf

Kheder, S. B., \& Zugravu, N. (2012). Environmental regulation and French firms location abroad: An economic geography model in an international comparative study. Ecological Economics, 77, 48-61. https://doi.org/10.1016/j.ecolecon.2011.10.005

Levinson, A. (1996). Environmental regulations and manufacturers' location choices: Evidence from the census of manufactures. Journal of Public Economics, 62(1-2), 5-29. https://doi.org/10.1016/0047-2727(96)01572-1

Mulatu, A., Gerlagh, R., Rigby, D., \& Wossink, A. (2010). Environmental regulation and industry location in Europe. Environmental and Resource Economics, 45(4), 459-479. https://doi.org/10.1007/s10640-009-9323-3

Porter, M. E. (1991). America's green strategy. Scientific American, 264(4), 168.

Porter, M. E., \& Van der Linde, C. (1995). Toward a new conception of the environment-competitiveness relationship. The Journal of Economic Perspectives, 9(4), 97-118. https://doi.org/10.1257/jep.9.4.97

Smarzynska, B. K., \& Wei, S. J. (2001). Pollution havens and foreign direct investment: dirty secret or popular myth? National Bureau of Economic Research. https://www.nber.org/papers/w8465

Stafford, S. L. (2000). The impact of environmental regulations on the location of firms in the hazardous waste management industry. Land Economics, 569-589. https://doi.org/10.2307/3146953

Tobey, J. A. (1990). The effects of domestic environmental policies on patterns of world trade: an empirical test. Kyklos, 43(2), 191-209. https://doi.org/10.1111/j.1467-6435.1990.tb00207.x

Train, K. E. (2009). Discrete choice methods with simulation. Cambridge University Press. 


\section{Notes}

Note 1. The distinction between the PHH and the pollution haven effect was postulated by Copeland and Taylor (2004). The PHH is much more controversial with little theoretical or empirical evidence to support it.

Note 2. Grossman and Krueger (1991) were the first to link the level of income to the demand for environmental quality in empirical research.

Note 3. Malta is excluded from the choice set because it did not import any waste during the study period (2007-2015).

Note 4. $U_{g j}$ becomes $U_{g i j}$ because in the dataset the same facility can appear several times. It is a repeated choice situation, which can be better modeled using a mixed logit approach.

Note 5. If a facility reported more than one shipment to the same country in the same year and slated for the same type of treatment (either disposal or recovery), it is counted as one shipment.

Note 6. More than 90 percent of hazardous waste stays within the EU. A small fraction of waste that has been shipped outside the EU is ignored in this study (except for Norway which is the only non-EU country included in the sample).

Note 7. The problem of confidentiality is very serious in the case of Belgium, which keeps most of its data confidential. European Commission seems to be aware of this issue (EC, 2009), but has not properly addressed it yet.

Note 8. Labor cost is more important in the case of a recovery facility. The price of land is crucial in the case of a landfill.

Note 9. The data on waste treatment capacity is available only for every second year. Therefore, I replaced missing values with values from the subsequent year.

Note 10. This prediction is consistent with the Porter hypothesis (see, e.g., Porter, 1991; Porter \& van der Linde, 1995; Ambec et al., 2013).

Note 11. The energy consumption component of the energy efficiency variable has been climate corrected using Eurostat's CHDD (heating and cooling degree days).

Note 12. The procedure involves the following steps. First, I standardized the values of all three variables. Second, I computed the unweighted average of the variables' standardized values (Z-scores). Finally, I converted the index to a 1-100 scale.

Note 13. The authors changed their approach in the following years and published another paper, where instead of the conditional logit model, they fitted the nested logit model allowing a waste generator to first choose a treatment option and then the destination.

Note 14. Of course, disposal of hazardous waste in general is more expensive and more capital intensive than disposal of regular waste.

Note 15. A researcher must choose a distribution for each random coefficient. In most applications, the distribution is specified to be normal or lognormal.

Note 16. The values of all other variables do not change.

Note 17. These calculations help to get a sense of the relative importance of studied variables. Obviously, in reality, it is hard to imagine that the disposal or recovery capacity of a country would increase dramatically without any change in other variables. 


\section{Appendix}

Table A1. Change in predicted probabilities from an increase of Total Cap. by 1 SD (calculated for Model (3))

\begin{tabular}{lrrrrr}
\hline Country & $\begin{array}{r}\text { Predicted } \\
\text { Probabilities }\end{array}$ & $\begin{array}{r}\text { Probabilities } \\
\text { after an increase } \\
\text { in Total Cap. }\end{array}$ & $\begin{array}{r}\text { Difference in } \\
\text { Predicted } \\
\text { Probabilities }\end{array}$ & $\begin{array}{r}\text { Percentage } \\
\text { Change }\end{array}$ & SER \\
\hline Norway & 0.024 & 0.035 & 0.011 & 45.833 & 99.629 \\
Luxembourg & 0.013 & 0.025 & 0.012 & 92.308 & 90.018 \\
Denmark & 0.006 & 0.011 & 0.005 & 83.333 & 73.903 \\
Sweden & 0.008 & 0.014 & 0.006 & 75.000 & 69.838 \\
Germany & 0.348 & 0.475 & 0.127 & 36.494 & 61.351 \\
France & 0.109 & 0.213 & 0.104 & 95.413 & 55.515 \\
Finland & 0.010 & 0.014 & 0.004 & 40.000 & 49.830 \\
United Kingdom & 0.077 & 0.125 & 0.048 & 62.338 & 48.913 \\
Netherlands & 0.084 & 0.186 & 0.102 & 121.429 & 43.753 \\
Ireland & 0.019 & 0.022 & 0.003 & 15.789 & 42.151 \\
Austria & 0.024 & 0.033 & 0.009 & 37.500 & 40.365 \\
Latvia & 0.003 & 0.004 & 0.001 & 33.333 & 38.563 \\
Slovenia & 0.007 & 0.009 & 0.002 & 28.571 & 37.805 \\
Lithuania & 0.002 & 0.003 & 0.001 & 50.000 & 32.738 \\
Italy & 0.028 & 0.051 & 0.023 & 82.143 & 30.499 \\
Spain & 0.015 & 0.022 & 0.007 & 46.667 & 29.529 \\
Belgium & 0.163 & 0.240 & 0.077 & 47.239 & 25.063 \\
Romania & 0.006 & 0.014 & 0.008 & 133.333 & 25.037 \\
Estonia & 0.002 & 0.003 & 0.001 & 50.000 & 21.910 \\
Poland & 0.006 & 0.014 & 0.008 & 133.333 & 21.142 \\
Cyprus & 0.004 & 0.005 & 0.001 & 25.000 & 20.168 \\
Croatia & 0.005 & 0.007 & 0.002 & 40.000 & 16.977 \\
Hungary & 0.004 & 0.007 & 0.003 & 75.000 & 14.249 \\
Bulgaria & 0.008 & 0.014 & 0.006 & 75.000 & 13.439 \\
Slovakia & 0.004 & 0.006 & 0.002 & 50.000 & 11.013 \\
Czech Republic & 0.005 & 0.008 & 0.003 & 60.000 & 10.663 \\
Portugal & 0.006 & 0.008 & 0.002 & 33.333 & 4.501 \\
Greece & 0.010 & 0.014 & 0.004 & 40.000 & 2.256 \\
\hline & & & &
\end{tabular}

\section{Copyrights}

Copyright for this article is retained by the author(s), with first publication rights granted to the journal.

This is an open-access article distributed under the terms and conditions of the Creative Commons Attribution license (http://creativecommons.org/licenses/by/4.0/). 